\title{
O PAPEL DA EDUCAÇÃO ESCOLAR NA CONSTRUÇÃO DE CONHECIMENTO EM TEMPOS DE DOMÍNIO DO MERCADO
}

\author{
EL PAPEL DE LA EDUCACIÓN ESCOLAR EN LA CONSTRUCCIÓN DE \\ CONOCIMIENTO EN TIEMPOS DE DOMINIO DEL MERCADO
}

\author{
THE ROLE OF SCHOOL EDUCATION IN CONSTRUCTION OF KNOWLEDGE IN \\ MARKET DOMAIN TIMES
}

Elita Betania de Andrade MARTINS ${ }^{1}$

\begin{abstract}
RESUMO: O presente artigo é parte das reflexões que vêm sendo desenvolvidas em uma pesquisa intitulada "Que educação para que país?", a qual tem por objetivo identificar possíveis transformações nas práticas docentes e gestoras, reconhecidas pelos professores e gestores da rede pública de Minas Gerais como decorrentes das atuais políticas educacionais. Os estudos têm indicado um percurso de construção de uma proposta de educação para o país desenvolvida em meio a debates e conflitos em relação à forma de se construir uma sociedade e uma perspectiva de educação que a sustente. Neste debate, forças diversas têm atuado no sentido de influenciar o trabalho e os conhecimentos escolares, sendo possível constatar a predominância de uma lógica voltada aos interesses de mercado e competitividade.
\end{abstract}

PALAVRAS-CHAVE: Educação. Mercado. Escola. Conhecimento.

RESUMEN: El presente artículo es parte de las reflexiones que vienen siendo desarrolladas en una investigación titulada "Qué educación para qué país?" La cual tiene por objetivo identificar posibles transformaciones en las prácticas docentes y gestoras, reconocidas por los profesores y gestores de la red pública de Minas Gerais como resultantes de las actuales políticas educativas. Los estudios han indicado un recorrido de construcción de una propuesta de educación para el país desarrollada en medio de debates y conflictos en relación a la forma de construir una sociedad y una perspectiva de educación que la sustenta. En este debate, fuerzas diversas han actuado en el sentido de influenciar el trabajo y los conocimientos escolares, siendo posible constatar la predominancia de una lógica volcada a los intereses de mercado y competitividad.

PALABRAS CLAVE: Educación. Mercado. Escuela. Conocimiento.

ABSTRACT: This article is part of the reflections that have been developed in a research entitled "What education for what country?" Which aims to identify possible transformations in teaching and management practices recognized by the teachers and managers of the public network of Minas Gerais as a result of current educational policies. The studies have indicated a course of construction of a proposal of education for the developed country amidst debates and conflicts regarding the way to build a society and an educational

${ }^{1}$ Universidade Federal de Juiz de Fora (UFJF), Juiz de Fora - MG - Brasil. Professora Adjunta da Faculdade de Educação/UFJF. Coordenadora do grupo de pesquisa GESE. E-mail: elita.martins @ufjf.edu.br

RPGE- Revista on line de Política e Gestão Educacional, Araraquara, v.22, n.1, p. 322-335, jan./abr. 2018 ISSN: 1519-9029 DOI: $10.22633 /$ rpge.v22.n.1.2018.10721 
perspective that supports it. In this debate, diverse forces have acted to influence the work and the school knowledge, being possible to verify the predominance of a logic directed to the interests of market and competitiveness.

KEYWORDS: Education. Market. School. Knowledge.

\section{Introdução}

O presente artigo é parte das reflexões que vêm sendo desenvolvidas pelo grupo GESE (Grupo de Estudos em Sistemas de Ensino) em uma pesquisa intitulada "Que educação para que país?"2, a qual tem por objetivo identificar possíveis transformações nas práticas docentes e gestoras, reconhecidas pelos professores e gestores da rede pública de Minas Gerais como decorrentes das atuais políticas educacionais.

Os estudos têm indicado um percurso de construção de uma proposta de educação para o país desenvolvida em meio a debates e conflitos em relação à forma de se construir uma sociedade e uma perspectiva de educação que a sustente. Assim, nos propomos neste texto, a refletir sobre como as políticas publicas atuais têm contribuído para que a escola legitime determinados conhecimentos, sobretudo aqueles que atendem as demandas de determinado modelo de desenvolvimento. Para isso, inicialmente, traçaremos um breve histórico sobre o papel da educação a serviço das diferentes classes sociais; em seguida, abordaremos o contexto atual e a sua influência na escola; discutindo o redesenho dos conhecimentos escolares a partir da atuação de diferentes forças e, finalmente, apresentaremos algumas considerações.

\section{Uma educação para cada classe?}

Como afirma Brandão (2007, p. 7) "ninguém escapa da educação", ela existe mesmo onde não exista escola, mas sempre que em uma sociedade aconteça a transferência de saber, muitas vezes de uma geração a outra.

Nas comunidades primitivas, as crianças aprendiam com os adultos, já que os acompanhavam na realização dos trabalhos. À medida que a vida dessas comunidades tornase mais complexa, assistimos ao aparecimento das classes sociais e a substituição da propriedade comum pela propriedade privada e como afirma Ponce (1982)

${ }^{2}$ Projeto de pesquisa financiado pela FAPEMIG com previsão de término no primeiro semestre de 2019. 
[...] com o desaparecimento dos interesses comuns a todos os membros iguais de um grupo e a substituição por interesses distintos, pouco a pouco antagônicos, o processo educativo, que até então era único, sofreu uma partição: a desigualdade econômica entre os "organizadores" - cada vez mais exploradores - e os "executores" - cada vez mais explorados - trouxe necessariamente, a desigualdade das educações respectivas. (PONCE, 1982, p. 26)

Assim, com a divisão social, passa a ser oferecido a cada classe, o conhecimento que a sociedade acreditava ser necessário possuírem, classes sociais distintas aprenderiam conhecimentos distintos.

Além disso, é importante destacar que a cada época da história, há uma compreensão do que é ser educado. Em Esparta, a educação visava à superioridade militar; em Roma, o homem educado era o "orador", hábil na arte de falar. Na Idade Média, sob forte influência da Igreja, que através dos monastérios, iniciam as primeiras "escolas" 3 " medievais, a educação com caráter instrutivo desenvolve atividades voltadas para os futuros monges e para os plebeus, entretanto, como nos alerta Ponce (1982, p. 91) “A finalidade dessas escolas não era instruir a plebe, mas familiarizar as massas campesinas com as doutrinas cristãs e, ao mesmo tempo, mantê-las dóceis e conformadas".

A partir das grandes navegações, há uma demanda para que as escolas se adéquem aos interesses dos comerciantes e banqueiros, assim é ressaltada a importância dos conhecimentos da Aritmética e da Geografia, em escolas denominadas por Ponce (1982, p.106) como "escolas de contabilidade". O referido autor destaca que o fortalecimento da burguesia, resulta na valorização dos conhecimentos úteis à vida, e com a Revolução francesa, aquilo que se apresentou como uma defesa dos "filhos da pátria", logo revelou que a substituição do regime feudal pelo burguês, não melhorou a vida da maioria da população, sendo defendida uma lógica de educação com o objetivo de "formar indivíduos aptos para a competição do mercado, esse foi o ideal da burguesia triunfadora." (PONCE, 1982, p. 135).

Se um breve resgate de nossa história revela a educação voltada a um projeto de sociedade idealizado por uma classe social que se configura como dominante, o que o contexto atual nos revela? Que educação vem sendo defendida? Quais conhecimentos são valorizados? Para que sociedade?

\section{$O$ contexto atual e a sua influência na escola}

${ }^{3}$ A instituição escolar segundo Canário (2006) é uma invenção histórica ocorrida nos finais do séc. XVIII, na transição do Feudalismo para a Era Moderna.

RPGE- Revista on line de Política e Gestão Educacional, Araraquara, v.22, n.1, p. 322-335, jan./abr. 2018 ISSN: 1519-9029 
Para refletirmos sobre a influência das políticas educacionais brasileiras nos conhecimentos que vêm sendo valorizados na escola atual, compreendemos ser necessário tratar questões sobre o contexto econômico que projetam o atual modelo de educação, para em seguida, tratarmos de propostas ligadas a este modelo que tem influenciado o trabalho da escola e do próprio docente.

Inicialmente, destacamos que, conforme Dardot e Lavall (2016), foi um erro de diagnóstico, acreditar que a crise financeira de 2008, que abalou os EUA e o mundo significasse a "morte" do pensamento neoliberal ${ }^{4}$. Na verdade, ele se reformulou, se fortaleceu. Aperfeiçoa-se a lógica de troca, aprofundando em todos os níveis a lógica da concorrência. Ao contrário do que muitos pensavam e sinalizavam como o fim do Estado em um modelo neoliberal, o que percebemos é que a este Estado, se atribui uma nova função, a de contribuir para a construção do mercado, ao mesmo tempo em que se submete as normas deste mercado.

Nas palavras de Ball (apud ROSA, 2013, p. 461) "o Estado hoje faz o papel de 'parteiro' (midwife), produzindo relações de mercado dentro das quais o setor privado tem a possibilidade de desenvolver atividades lucrativas na execução e gestão dos serviços públicos”. Assim, assistimos a cada dia, direitos se transformarem em bens, produtos a serem adquiridos conforme a capacidade individual de consumo.

Frequentemente, observamos que o neoliberalismo tem se tornado, muito mais do que um sistema político e econômico, acaba por se constituir em uma racionalidade, em um modo de vida, na qual se generaliza a concorrência e se constrói uma subjetividade, estamos a cada dia, "introjetando em nossos poros", uma determinada forma de ser e agir, pautada na competição e na busca para o sucesso.

Para clarear essa construção de um novo sujeito, destacamos novamente, Ball (apud ROSA, 2013, p. 462) que afirma "Os sujeitos neoliberais são empreendedores, criativos, solipsistas, individualistas, e desenvolvem um tipo de subjetividade que o neoliberalismo necessita para sobreviver”. Para a construção desta subjetividade, vários instrumentos serão utilizados, podendo ser aqui destacados a opinião de especialistas, o trabalho da imprensa ${ }^{5}$, e

${ }^{4}$ Modelo político econômico que nasce depois da 2. ${ }^{a}$ Guerra Mundial, na Europa e na América do Norte, como uma reação teórica e política contra o Estado do Bem Estar Social e que defende uma redução na atuação do Estado e a liberdade de mercado. Propõe o desenvolvimento de medidas como: disciplina fiscal , redefinição de gastos públicos, reforma tributária, liberalização do setor financeiro e comercial, manutenção de taxas de câmbio competitivas, atração das aplicações de capital estrangeiro, privatização de empresas estatais, desregulação da economia.

5 Vale destacar que no ano de 2016, uma emissora de TV, propôs na semana da criança, que pequenos repórteres apresentassem matérias sobre empreendedorismo, a partir do tema "Empreender: quem muda o mundo em que eu vivo"$<$ http://g1.globo.com/minas-gerais/triangulo-mineiro/noticia/2016/08/inscricoes-para-concurso-reporter-mirim-2016-vao-ate-29de-setembro.html>. 
também, a tentativa de condução de um projeto de educação, afinal como tratamos anteriormente, a cada momento histórico exigiu-se um modelo de educação. Mas que modelo de educação tem sido desenhado para atender ao pensamento neoliberal e consequentemente, que tipo de conhecimento a escola tem valorizado?

Sob influência deste modelo neoliberal, desde a década de 1990, a educação brasileira vem sendo modelada a partir de acordos internacionais, dentro de uma lógica de "modernização" do Estado, ou seja, sua adequação a lógica de mercado. Começam a ser desenhadas políticas de descentralização, que na educação resultaram em diferentes graus de autonomia escolar. Mas essa aparente possibilidade, liberdade de escolhas, se desenvolve paralelamente a construção de um sistema de avaliação externa, envolvendo diversas e progressivas formas de avaliação, que inicialmente, funcionariam como um termômetro, um instrumento para diagnosticar a realidade escolar, mas que gradativamente, passaram a ser utilizadas em “rankings' escolares. Como afirma Dalila Oliveira (2007, p. 367) "O desempenho dos alunos passa a ser algo exaustivamente mensurado".

Se inicialmente, a prática de listar as escolas por ordem de classificação, criava insatisfação e resistência, passa na atualidade, a ser "naturalizada". É comum, ouvirmos depoimentos de pais e responsáveis, afirmando escolherem determinada escola, devido a seu desempenho em avaliações tais como o Exame Nacional do Ensino Médio (ENEM). O resultado de uma avaliação externa torna-se a indicação de uma escola ser ou não de qualidade, outros elementos como a proposta pedagógica, atividades extraclasse, ambiente acolhedor, são tratados como apêndices.

Devido a essa lógica, diretores passam a se preocupar em organizar o trabalho escolar de forma a obter os resultados esperados em tais avaliações, assim valorizam-se aquelas áreas de conhecimento, como por exemplo, Português e Matemática, eleitas para comporem questões em avaliações como a Prova Brasil, cujos resultados, aliados à dados de promoção são utilizados para cálculo do Índice de Desenvolvimento da Educação Básica (IDEB), o qual vem sendo considerado parâmetro de qualidade.

Por esta razão, as escolas passam a priorizar tais áreas de conhecimento e as atividades apontadas como diretamente responsáveis pelos resultados desejados, não é à toa que muitos esforços têm sido despendidos para garantir a oferta da educação física nas escolas, como foi o caso de Minas Gerais ${ }^{6}$, onde uma Resolução, em 2013, dispensava a obrigatoriedade dos profissionais de educação física no trabalho dos anos iniciais do ensino fundamental, e da

6 Vide <http://g1.globo.com/minas-gerais/triangulo-mineiro/noticia/2013/03/profissionais-de-educacao-fisicacontestam-resolucao-em-mg.html>. 
grande discussão em torno da importância desta área de conhecimento, por ocasião da Medida Provisória n. ${ }^{\circ} 746 / 2016$, que reformulava o ensino médio, estabelecendo entre outras medidas a não obrigatoriedade de disciplinas como artes e educação física nesta etapa de ensino, indicando que tais áreas de conhecimento não são fundamentais para o modelo de educação que se pretende implantar.

Neste contexto, o papel da gestão escolar não se limita a organizar o trabalho da escola para produção de resultados, que atestarão a qualidade institucional, é também o de desenvolver estratégias de marketing que auxiliem na divulgação do desempenho obtido pela escola e aí, é fácil identificar pelas ruas da cidade, banners, outdoors, onde podemos encontrar estampados os rostos dos alunos "bem sucedidos" em avaliações, "os melhores", aqueles que atestam a qualidade do produto educacional a ser consumido. Esta proposta de divulgação de qualidade, não só alimenta a competição entre alunos e escolas, como também, contribui para o desrespeito à diversidade, afinal todos devem se adequar ao modelo de sucesso, apontado como o melhor, o que, muitas vezes, resulta na exclusão dos não bem-sucedidos. Assim, se na Antiguidade, a educação espartana visava sujeitos que dominassem os conhecimentos necessários à supremacia militar, hoje, a educação parece buscar a preparação de sujeitos bem-sucedidos, antenados com as necessidades do mercado.

\section{O redesenho dos conhecimentos escolares: As forças atuantes}

$\mathrm{Na}$ definição dos conhecimentos considerados importantes ao preparo de sujeitos bem-sucedidos, passam a ser consultados os especialistas em sucesso no mercado, os empresários. Estes, cada vez mais se fazem presentes nas discussões educacionais, através da atuação de Organizações não Governamentais ( $\left.\mathrm{ONG}^{\prime} \mathrm{s}\right)$ que prestam consultorias às Secretarias de Educação, oferecendo cursos de aperfeiçoamento ou elaborando materiais didáticos com a finalidade de auxiliar aos professores. Como bem destaca Elizabeth Macedo (2014), ao se referir à discussão da Base Nacional Comum Curricular (BNCC)

Paralelamente, agentes sociais privados apareciam no cenário da educação, buscando interferir nas políticas públicas para a educação também com perspectivas de maior controle sobre os currículos. Fundações ligadas a conglomerados financeiros como Roberto Marinho, Victor Civita, Airton Senna e Lemann, empresas como Natura, Gerdau e Volkswagen, grupos educacionais como CENPEC e "movimentos" como o Todos pela Educação são alguns dos exemplos. (MACEDO, 2014, p. 1533) 
Este último movimento destacado por Macedo (2014) organizou uma página ${ }^{7}$ para acompanhamento das ações do PNE 2014/2024 e teve forte influência na elaboração do Plano de Desenvolvimento da Educação em 2007, na gestão Lula, que dentre outras medidas criou o já referido IDEB. Vale ressaltar como destacado por Paulo Mello (2015) que apesar dos governos do $\mathrm{PT}^{8}$ terem representado a ascensão de projetos populares voltados à inclusão e diversidade, emitiram "sinais dúbios" na política educacional, muitas vezes, submetendo o campo educacional a lógica de mercado. Assim, mesmo diante de um projeto educativo mais inclusivo e popular, os interesses corporativos se fizeram presentes na definição de um modelo de educação que reorganiza o trabalho escolar e redefine conhecimentos a serem priorizados, a partir da formulação de currículos.

A atuação dos empresários na área educacional e na formulação de currículos foi abordada por Ivor Goodson

[...] esses interesses corporativos que controlam a televisão, a maioria dos jornais e basicamente conseguiram o controle da narrativa. Eles promovem e impulsionam as mudanças; eles podem dizer "nós precisamos de testes, e precisamos de professores mais responsáveis, precisamos deste currículo, precisamos de um currículo que seja mais econômico, não precisamos de Sociologia, nós precisamos [...]' (GOODSON, apud MELLO, 2014, grifos nossos)

Os empresários, como classe dominante, indicam o conhecimento que acreditam ser importante para a construção de um modelo de homem, bem-sucedido, em uma sociedade marcada pela competição de mercado.

Vale ressaltar que esta aproximação de empresários e educação é um movimento internacional como destaca Ball (apud ROSA, 2013), entretanto, pensando em Brasil, podemos eleger algumas ações, como por exemplo, a atuação da organização Movimento Brasil Competitivo (MBC) mantido por empresas como a Gerdau, Fiat, Eurofarma, Natura entre outras e que é parceira no programa de modernização "gestão por resultados" da Secretaria de Educação de Pernambuco, estado apontado como modelo, pelo atual Ministro de Educação Mendonça Filho, ao tratar da reorganização do ensino médio, no que se refere à implementação do tempo integral.

A preocupação com o mercado também parece estar presente na proposta de reorganização do ensino médio, implantada pela Medida Provisória MP 746/2016 e que

${ }^{7}$ Observatório do PNE.

${ }^{8}$ Referindo-se a gestão dos presidentes Luís Inácio Lula da Silva (2003-2011) e Dilma Rousself (2011-2016) ambos filiados ao Partido dos Trabalhadores (PT).

RPGE- Revista on line de Política e Gestão Educacional, Araraquara, v.22, n.1, p. 322-335, jan./abr. 2018 ISSN: 1519-9029 DOI: $10.22633 /$ rpge.v22.n.1.2018.10721 
posteriormente deu origem a Lei n ${ }^{\circ} 13415 / 2017^{9}$. O Secretário de Educação Básica Rossieli Soares da Silva em entrevista ${ }^{10}$, justificou a reforma via medida provisória, por não haver tempo a perder:

\begin{abstract}
a nossa população de jovens será menor do que a nossa população de idosos, o peso vai ser maior, de novo, para a previdência. E o movimento da nossa economia precisa do jovem trabalhador, que faz a máquina girar, precisa do jovem empreendedor que vai criar e gerar riqueza para o país, para que o país seja sustentável. Se a gente não mexer nisso com urgência, para gente poder gerar um efeito para 2018, 2019, se não fosse por MP teríamos que assumir que a reforma do Ensino Médio não é importante, que manter todas as disciplinas obrigatórias em um Ensino Médio engessado que não tem possibilidades para o jovem não é importante (SILVA, 2016, s/p, grifos nossos).
\end{abstract}

O uso da Medida provisória para reformulação do ensino médio buscaria, então, atender a necessidade de nossa economia, de "fazer a máquina girar". O atual governo afirma que a reforma permitirá maior autonomia para os alunos, já que além das $1800 \mathrm{~h}$ da carga horária total dedicada aos conteúdos estabelecidos na BNCC, poderão utilizar as horas restantes nos itinerários formativos e na parte diversificada definida por cada sistema de ensino.

Apesar da propaganda ${ }^{11}$ de autonomia, de liberdade de escolha, veiculada na imprensa, a Lei 13415/2017 estipula que "A organização das áreas de que trata o caput e das respectivas competências e habilidades será feita de acordo com critérios estabelecidos em cada sistema de ensino." (art.36, $\S 1^{\circ}$ ), assim, a escolha dos alunos, sobretudo os de escolas públicas terá que ser feita a partir das ofertas disponíveis.

A reforma do ensino médio parece refletir uma preocupação com a preparação rápida para o mercado de trabalho, a partir do momento em que estabelece à viabilidade de se incorporar a experiência prática de trabalho, no setor produtivo, para oferta da formação profissional e a possibilidade de aproveitamento de conteúdos cursados no ensino médio para computação de créditos no ensino superior. Tais medidas podem representar uma entrada cada vez mais precoce do jovem, sobretudo os mais pobres, no mercado de trabalho, constituindo-

\footnotetext{
${ }^{9}$ Altera as leis nos 9.394, de 20 de dezembro de 1996, que estabelece as diretrizes e bases da educação nacional, e 11.494, de 20 de junho 2007, que regulamenta o fundo de manutenção e desenvolvimento da educação básica e de valorização dos profissionais da educação, a consolidação das leis do trabalho - clt, aprovada pelo decreto- lei $\mathrm{n}^{\circ} 5.452$, de $1^{\circ}$ de maio de 1943 , e o decreto-lei $\mathrm{n}^{\circ} 236$, de 28 de fevereiro de 1967 ; revoga a lei $\mathrm{n}^{\circ} 11.161$, de 5 de agosto de 2005; e institui a política de fomento à implementação de escolas de ensino médio em tempo integral.

${ }^{10}$ Revista Mapa Educação <http://mapaeducacao.com/blog/>, em 15/10/16.

11 Leia sobre o assunto em <https://jornalggn.com.br/noticia/propaganda-esconde-defeitos-da-reforma-doensino-medio-alerta-callegari>.
} 
se em força de trabalho precarizada. Vale lembrar que conforme dados do $\operatorname{PNAD}^{12}$ (2011), do total de adolescentes de 15 a 17 anos empregados, apenas 30,4\% têm carteira assinada, o que poderá ainda diminuir considerando que após a Reforma trabalhista, há a possibilidade de um trabalhador ser contratado por uma empresa como autônomo, sem a necessidade de carteira $\operatorname{assinada}^{13}$.

Este novo modelo de educação, que vem sendo desenhado, implica em mudanças não só na gestão escolar e no desenho do currículo, mas também no trabalho docente. Para o repasse do conhecimento necessário a produção de desempenho, um novo perfil de professor é requisitado. Há o fortalecimento de um discurso de importância do trabalho docente, tratado como "salvador da pátria" (LUDKE; BOING, 2004, p. 1175), o que necessariamente, não representa reconhecimento profissional, mas sim uma manobra para aumentar a responsabilização docente, atribuindo a este, responsabilidades por resolver problemas e situações que estão muito além dos seus limites. Como afirma Brito

[...] o atual discurso enfatiza que ao professor corresponde a tarefa de responder a situações cotidianas no seu local de trabalho e aprender seu novo perfil social. Relativizam-se os aspectos sócio-políticos à medida que ao professor cumpre realizar seu trabalho independentemente do contexto e das condições reais de sua escola e de suas relações de trabalho (BRITO, 2009, p. 93, grifos nossos).

Brito (2009) aponta que as questões sócio-políticas são relativizadas, pois parte-se do princípio que os problemas enfrentados pelos professores em seu trabalho, podem ser resolvidos a partir de domínio de conhecimentos técnicos, obtidos em diversos cursos de formação a serem oferecidos a grande "massa de professores", do norte ao sul do país como se todos enfrentassem as mesmas dificuldades.

Este professor "técnico", quase visto como um instrutor, tem seu profissionalismo reconhecido a partir do momento em que seus alunos produzem os resultados esperados nas avaliações externas ${ }^{14}$, atestando sua capacidade de performance (BALL, 2005). Além disso, podemos afirmar que este professor técnico tem seu trabalho submetido a um novo controle, como afirma Goodson (apud Mello, 2014)

${ }^{12}$ Pesquisa Nacional por Amostra de Domicílio.

13 "Quem ganha e quem perde com 10 propostas da reforma trabalhista" <http://www1.folha.uol.com.br/mercado/2017/05/1881775-quem-ganha-e-quem-perde-com-10-propostas-dareforma-trabalhista.shtml>.

${ }^{14}$ Talvez, cada um de nós conheça um professor que passou a ser mais bem visto, por ter acertado o tema que foi abordado na produção de texto do ENEM.

RPGE- Revista on line de Política e Gestão Educacional, Araraquara, v.22, n.1, p. 322-335, jan./abr. 2018 
O controle é bem rígido, uma gaiola de ferro de controle neoliberal assegurando que nenhum tipo de conhecimento poluído, nenhum tipo de conhecimento radical, social, útil ou alternativo consiga entrar em sala de aula (GOODSON apud MELLO, 2014, p. 7, grifos nossos)

A gaiola de ferro neoliberal busca proteger o ambiente escolar e os conhecimentos indicados como importantes para a formação de sujeitos bem-sucedidos, de influências não desejadas, mas que influências seriam estas?

Dardort e Lavall (2014, p. 382) questionam: “Quando o desempenho é o único critério de uma política, que importância tem o respeito à consciência, à liberdade de pensamento e expressão?". Tal questionamento pode servir de alerta sobre quais conhecimentos passam a não ser priorizados na escola, além disso, quando consideramos outro alerta feito pelos referidos autores de que a racionalidade neoliberal "pode articular-se a ideologias estranhas à pura lógica mercantil sem deixar de ser a racionalidade dominante", citando como exemplo, o moralismo neoconservador, fica mais fácil compreender o crescimento de movimentos como o "Escola sem Partido" aqui no Brasil.

Tal movimento foi criado pelo advogado Miguel Nagib, em 2004 e hoje, conta vários defensores pelo país. Nas palavras de Fernando Pena $(2016)^{15}$

Desde 2004, os setores mais conservadores estão falando sobre o Escola Sem Partido e nós os deixamos falar, sem uma oposição consistente a esse discurso. Enquanto nós o considerávamos uma grande besteira, "coisa de malucos", ele se propagou e, agora, eles estão ganhando força. Tanto que um dos primeiros atos do ministro Mendonça Filho (Educação) foi receber uma comitiva dos Revoltados Online movimento que nunca levaríamos a sério com o Alexandre Frota para defender essa pauta. (PENNA, 2016, s/p.)

O movimento afirma defender a liberdade de aprender do aluno e ser contrário à doutrinação que este grupo acredita que os docentes façam junto aos alunos. Para os seus defensores, um aluno pode ser vítima de doutrinação ideológica quando seu professor se desvia frequentemente da matéria objeto da disciplina para assuntos relacionados ao noticiário nacional e internacional, o que nos indica a compreensão que este movimento tem sobre os conhecimentos que devem ser trabalhados na escola.

É possível identificar no discurso dos defensores do "Escola sem Partido", a ideia de desvalorização da figura do professor, "Nenhum pai é obrigado a confiar em um professor" $\left(\right.$ NAGIB, 2016) ${ }^{16}$ e a compreensão de um professor técnico, instrutor, já que uma

15 O que está por trás do 'Escola Sem Partido'? entrevista concedida à Carta Maior em 20/07/16. <http://cartamaior.com.br/?/Editoria/Politica/OqueestaportrasdoEscolaSemPartido/4/36486 1/>.

${ }^{16}$ Trecho de debate realizado na GloboNews. Disponível em $<$ https://www.youtube.com/watch?v=iNSC1rNOz74\&feature=youtu.be>. 
característica dessa concepção de escolarização é a proibição de mobilizar valores de qualquer natureza (PENNA, 2017), dentre esses valores a não serem trabalhados, encontra-se a cidadania, como pode ser constatado a partir da afirmação apresentada na página do movimento "Escola sem Partido" : "78\% dos professores brasileiros acreditam que a principal missão das escolas é 'formar cidadãos' (expressão que na prática se traduz, como todos sabem, por fazer a cabeça dos alunos)" 17

Tal concepção afirma que a maioria dos professores diz querer "despertar a consciência crítica", o que segundo o "Escola sem Partido", consiste "apenas e tão somente em martelar ideias de esquerda na cabeça dos estudantes" ${ }^{18}$, o que na concepção do movimento não devem ser conhecimentos trabalhados na escola, pois segundo consta em seu site:

Como se sabe, a visão crítica dos estudantes é direcionada sempre e invariavelmente para os mesmos alvos: a civilização ocidental, o cristianismo, os valores cristãos, a Igreja Católica, a "burguesia", a família tradicional, a propriedade privada, o capitalismo, o livre-mercado, o agronegócio, o regime militar, os Estados Unidos, etc. ${ }^{19}$

Para protegerem os alunos, vistos como vítimas de um processo de doutrinação, os defensores do movimento propõem a fixação de um cartaz com deveres do professor, com a finalidade de facilitar o trabalho dos pais e alunos no combate a doutrinação e ainda, dispõem no site do movimento de um espaço para veiculação de denúncias feitas através de vídeos ou textos, sobre professores considerados doutrinadores. Tal prática, nos remete a Ponce (1982) que ao tratar da educação do homem antigo, e as mudanças sociais que ocorreram na Grécia, transformando relações e questionando até a disciplina mantida nas escolas, afirma que as classes dirigentes reagiram a esse ímpeto das novas classes

Por meio de um poderoso movimento de terror político e de vigilância pedagógica. Um decreto instigado pelo adivinho Dispeites exigiu que o povo denunciasse todos os que não prestavam homenagem às coisas divinas, ou que ensinavam teorias heterodoxas a respeito das coisas celestes [...] (PONCE, 1982, p. 56)

Assistimos assim, ao crescimento de um movimento que parece desejar a contenção da propagação de conhecimentos e ideias que possam questionar as crenças e valores de uma

17 Cópia de trecho de Dia Nacional de Luta contra a doutrinação nas escolas, disponível em: $<$ http://escolasempartido.org/dia-nacional-de-luta-contra-a-doutrinacao-politica-e-ideologica-nasescolashttp://escolasempartido.org/dia-nacional-de-luta-contra-a-doutrinacao-politica-e-ideologica-nas-escolas>. ${ }^{18}$ Disponível em: <http://escolasempartido.org/faq>.

${ }^{19}$ Trecho do texto A doutrinação é um problema grave na educação brasileira? Por quê? - disponível em $<$ http://escolasempartido.org/faq >

RPGE- Revista on line de Política e Gestão Educacional, Araraquara, v.22, n.1, p. 322-335, jan./abr. 2018 
classe dominante. Para que esta concepção se materialize pressões e discursos de convencimento são feitos junto aos ocupantes de cargos legislativos não só nas Câmaras municipais e estaduais, como também, no Congresso Nacional e resultam na apresentação de Projetos de Lei como o PL 7180/14 ${ }^{20}$, o PL 867/15²1 e o PL 193/16 22 , dentre outros.

Vale ressaltar que o nome do Movimento "Escola sem Partido" agrada a muitos, com base na crença que uma escola não pode estar a serviço de nenhum partido, mas como abordamos anteriormente, há indícios de o que se busca, na verdade, é constituir uma força tarefa que controle o pensamento e fala do professor, sobretudo quando se aproxima do chamado "pensamento de esquerda" ou representa críticas ao modelo segregador que vem sendo construído e marcado por uma ideia de educação para a formação do ser humano bem sucedido, em um mundo marcado por uma lógica competitiva de mercado.

\section{Algumas considerações}

As ideias de uma educação escolar que enfatize áreas de conhecimento como Português e matemática ou outras consideradas necessárias para a performance desejada em avaliações externas, que inculta nos alunos pensamentos de que são os melhores, os mais bem sucedidos e que busca neutralizar quaisquer influência de aspectos sócio-político, e de criticidade, transformando o conhecimento em algo tecnificado, objetivado, empacotado, vêm ganhando força na realidade brasileira e interferindo no projeto político pedagógico das escolas.

Tal documento, previsto na Lei de Diretrizes e Bases da Educação Nacional (LDB Lei ${ }^{\circ}$ 9394/96) e que deve representar a identidade escolar, vem sendo modelado de forma a garantir o desempenho satisfatório e assim, contribuir para que a escola possa configurar nas diferentes listas de divulgação das consideradas melhores escolas. Como tratado anteriormente, determinadas áreas do conhecimento são relegadas a segundo plano, e outros conhecimentos passam a ser incorporados, como é o caso da disciplina empreendedorismo

\footnotetext{
${ }^{20}$ De autoria do deputado Erivelton Santana PSC/BA que propõe alteração na LDB, incluindo entre os princípios do ensino o respeito às convicções do aluno, de seus pais ou responsáveis, dando precedência aos valores de ordem familiar sobre a educação escolar nos aspectos relacionados à educação moral, sexual e religiosa

${ }^{21}$ Apresentado pelo deputado Izalci PSDB/DF Inclui, entre as diretrizes e bases da educação nacional, o "Programa Escola sem Partido".

${ }^{22}$ Do senador Magno Malta PR/ES Inclui entre as diretrizes e bases da educação nacional, de que trata a Lei ${ }^{\circ}$ 9.394, de 20 de dezembro de 1996, o "Programa Escola sem Partido".
} 
que vem sendo agregada não só no currículo do ensino médio, como até mesmo, na educação infantil ${ }^{23}$.

Talvez, estejamos assistindo uma privatização do espaço público da escola, não no sentido de se adotar cobranças de taxas ou de se desvincular do Estado como mantenedor, mas ao incorporar no seu contexto uma concepção de educação mercadológica, pautada pelo individualismo, pela competição e por crenças que só respeitam outras formas semelhantes a sua.

Acreditamos que práticas avaliativas utilizadas para fomentar lógicas meritocráticas, reformas educativas feitas apressadamente com vistas a responder a demandas de mercado e projetos que buscam cercear o trabalho docente, têm marcado profundamente a construção do conhecimento na escola, estabelecendo o que deve ou não ser aprendido e são apenas alguns dos desafios a serem enfrentados por aqueles que abraçam a educação como profissão e aos setores da sociedade mais comprometidos com valores democráticos, inclusivos e populares.

AGRADECIMENTOS: À FAPEMIG - Fundação de Amparo e Pesquisa do Estado de Minas Gerais.

\section{REFERÊNCIAS}

BALL, Stephen J. Profissionalismo, gerencialismo e performatividade. Revista Cadernos de Pesquisa, v.35, n.126, p. 539-564, set./dez., 2005.

BRANDÃO, Carlos Rodrigues. O que é educação? São Paulo: Brasiliense, 2007

BRITO, Vera Lúcia Ferreira Alves de. Identidade docente: um processo de avanços e recuos. In: Professores: identidade, profissionalização e formação. Belo Horizonte, MG: Editora Argvmentvm, 2009, p.79-100.

CANÁRIO, Rui. A escola tem futuro? Das promessas às incertezas. Porto Alegre: Artmed, 2006.

DARDOT, Pierre.; LAVALL, Christian. A nova razão do mundo: ensaio sobre a sociedade neoliberal. São Paulo: Boitempo, 2016.

LUDKE, Menga.; BOING, Luiz Alberto. Caminhos da profissão e da profissionalidade docentes. Revista Educação \& Sociedade. Campinas, v.25, n.89, 2004.

23 É possível ler uma matéria que ilustra bem este cenário em <http://liessin.com.br/empreendedorismo-eassunto-de-crianca/>. 
MACEDO, Elizabeth. Base Nacional Curricular Comum: Novas formas de sociabilidade produzindo sentidos para educação. Revista e-Curriculum, São Paulo, v. 12, n. 03, p.15301555, out./dez., 2014.

MELLO, Paulo Eduardo Dias de. Base Nacional Comum, Direitos e Objetivos de Aprendizagem e Desenvolvimento e o IDEB : nexos, contextos, rastros e o lugar do professor. Disponível em: <www.academia.edu/9809465/Base_Nacional_Comum>. Acesso em 10 mar. 2017.

OLIVEIRA, Dalila Andrade de. Política educacional e a re-estruturação do trabalho docente: reflexões sobre o contexto latino-americano. Revista Educação e Sociedade, Campinas, v. 28, n. 99, p. 355-375, maio/ago., 2007.

PENNA, Fernando de Araujo. O Escola sem Partido como chave de leitura do fenômeno educacional. In: FRIGOTTO, Gaudêncio (Org.). Escola "sem" Partido: esfinge que ameaça a educação e a sociedade brasileira. Rio de Janeiro: UERJ, LPP, 2017.

PONCE, Anibal. Educação e luta de classes. $3^{\text {a }}$ edição. Tradução de José Severo de Camargo Pereira. São Paulo: Cortez, 1982.

ROSA, Sanny Silva da. Entrevista com Stephen J. Ball: Privatizações a educação e novas subjetividades - contornos e desdobramentos das políticas (pós) neoliberais. Revista Brasileira de Educação, v,18, n 53, abr-jun/2013

\section{Como referenciar este artigo}

MARTINS, Elita Betania de Andrade. O papel da educação escolar na construção de conhecimento em tempos de domínio de mercado. Revista on line de Política e Gestão Educacional, Araraquara, v.22, n.1, p. 322-335, jan./abr., 201. ISSN: 1519-9029. DOI: 10.22633/rpge.v22.n.1.2018.10721

Submetido em: 29/11/2017

Aprovado em: 29/03/2018 